\title{
E. P. THOMPSON E A EDUCAÇÃO: A SOCIALIZAÇÃO COMO EXPERIÊNCIA ${ }^{1}$
}

\author{
Suely Aparecida Martins ${ }^{2}$
}

\begin{abstract}
RESUMO
Este artigo apresenta as possibilidades de análise da educação a partir das contribuições teóricas do historiador marxista Edward Palmer Thompson. Inicia-se com algumas considerações sobre concepções de educação que ora enfatizam seu papel para a conformação dos sujeitos a sociedade ora salientam que ela encontra-se inserida numa realidade constituída de significados. Contrapondo-se a tais perspectivas, destaca-se como a categoria "experiência" de Thompson pode contribuir para a análise dos processos educativos, considerando-se a materialidade social e a agência humana na história. Assim, primeiramente, apresenta-se a concepção do autor sobre "experiência" e em seguida, a importância desta categoria para a compreensão dos processos de socialização. Destaca-se a experiência como fundamental para analisar a educação, especialmente aquela que ocorre em espaços informais e que se constituem a partir de coletivos.

Palavras-chave: educação; socialização; experiência; Thompson
\end{abstract}

\section{EP THOMPSON AND EDUCATION: THE SOCIALIZATION AS EXPERIENCE}

\section{ABSTRACT}

This paper presents the possibilities of analysis of education from the theoretical contributions of the Marxist historian Edward Palmer Thompson. It starts with some considerations on conceptions of education that at times emphasize their role in shaping the society subjects and at times finds itself inserted in reality consisting of meanings. Opposed to such perspectives, stands out as the category experience of Thompson can contribute to the analysis of educational processes, considering the social materiality and human agency in history. So, first, we present the conception of the author about experience, and then the importance of this category to the understanding of socialization processes. It is highlighted the experience as fundamental to analyze education, especially the one which occurs in informal settings and are constituted from collectives.

Keywords: education; socialization; experience; Thompson

O objetivo deste artigo é apresentar as possibilidades de análise da educação a partir das contribuições teóricas do historiador marxista Edward Palmer Thompson. A partir da compreensão da educação como socialização destaca-se como a categoria experiência pode ser fundamental para a análise dos processos educativos, considerando-se a materialidade histórico-social.

Durkheim (1975), um dos principais autores no âmbito da sociologia clássica, definiu a educação como a "socialização metódica das novas gerações". Para ele, seria função da educação preparar as crianças e os jovens para a vida em sociedade, integrandoos aos seus valores e costumes e assim, garantindo sua continuidade.

Estudos realizados posteriormente, de certa forma, deram continuidade a esta perspectiva. Eisenstadt (1976), por exemplo, em seu estudo sobre as gerações, chamou a atenção para a importância dos processos de socialização para a integração dos jovens na 
sociedade. A família, a escola e os próprios grupos juvenis aparecem como agências socializadoras fundamentais nas sociedades modernas. Porém, em relação aos grupos juvenis, Eisenstadt (1976, p. 260), salienta que nem sempre cumprem funções integrativas na sociedade. Referindo-se aos grupos juvenis destaca: "Quando, entretanto, semearem a oposição às gerações mais velhas e aos seus valores, estarão assumindo cada vez mais um caráter anormativo".

Tal concepção reforça a perspectiva teórica de Eisenstadt (1976) que, baseado nos estudos funcionalistas, está preocupado com que os indivíduos ocupem os papéis ou posições requeridas pelo sistema social. A socialização das novas gerações, neste caso, é compreendida como necessária à integração e continuidade social.

Por sua vez, Berger e Luckmann (2002, p. 175) entendem a socialização como "a ampla e consistente introdução de um indivíduo no mundo objetivo de uma sociedade ou setor dela". Pode ser definida como: socialização primária, que ocorre durante a infância e tem na família seu núcleo principal; e socialização secundária, ou seja, "qualquer processo subseqüente que introduz um indivíduo já socializado em novos setores do mundo objetivo de sua sociedade". É a partir da interiorização dos outros significativos presentes no mundo objetivo que o indivíduo constrói sua subjetividade. Ou seja, o indivíduo torna-se o que é por meio de um processo dialético "entre a identificação pelos outros e a autoidentificação, entre a identidade objetivamente atribuída e a identidade subjetivamente apropriada" (BERGER; LUCKMANN, 2002, p. 177).

Entretanto, se, na socialização primária, não existe problema de identificação, uma vez que as possibilidades de escolha estão limitadas pelo universo familiar, ou seja, não se escolhe pais e irmãos, mas arranja-se com aqueles que se têm; na socialização secundária, o indivíduo é colocado frente a diversas instituições que podem ou não ser coerentes com os significados interiorizados pelo indivíduo durante a socialização primária. Nesse sentido, os processos de socialização também podem ser definidos a partir da relação estabelecida entre as diferentes gerações e as instituições a que estas se encontram ligadas. Salienta-se, no entanto, que tais análises, ao tratarem a realidade objetiva como um universo constituído de significados, ignoram que os processos de socialização encontramse inseridos numa determinada materialidade histórica, sendo por ela também influenciados.

Caberia entender os processos de socialização a partir da materialidade históricosocial em que eles acontecem. Neste sentido, as reflexões elaboradas pelo historiador marxista E. P. Thompson, se constituem como referência para ajudar a analisar esses processos considerados a partir de determinada materialidade histórico-social, discutindo as relações históricas a partir da categoria experiência como fundamental no processo educativo. Assim, num primeiro momento, apresenta-se como a categoria experiência é trabalhada por Thompson e em seguida, destaca-se a importância desta categoria para a análise dos processos de socialização. Aqui, acredita-se, a experiência adquire um caráter central para analisar a educação, especialmente aquela que ocorre fora das instituições escolares formais.

\section{A categoria experiência em Thompson}

São muitas as contribuições de Thompson para a história, a sociologia e também a educação. Não é à toa que Michel Lowy (1997), destaca ele como um dos autores marxistas do século XX importante para ser revisitado dado a originalidade de sua contribuição teórica-metodológica. Todavia, considerando o objetivo de elucidar a 
contribuição mais específica de Thompson para a educação deter-se-á a relevância da categoria experiência deste autor.

Considerando a totalidade de todo fenômeno social, em Thompson a experiência se constitui no processo histórico em que homens e mulheres encontram-se inseridos. Todavia, não se trata de seres abstratos, desprovidos da materialidade social que os condiciona, mas de homens e mulheres concretos, situados em condições sociais específicas:

Estamos falando de homens e mulheres, em sua vida material, em suas relações determinadas, em sua experiência dessas relações, e em sua autoconsciência dessa experiência. Por 'relações determinadas' indicamos relações estruturadas em termos de classe, dentro de formações sociais particulares (THOMPSON, 1981, p. 111).

A experiência, por sua vez, pressupõe a agência humana na história, ou seja, homens e mulheres pensam e agem a partir de determinada realidade e, conforme diz Thompson, respondem, individualmente ou em grupo "... a muitos acontecimentos interrelacionados ou a muitas repetições do mesmo tipo de acontecimento" (THOMPSON, 1981, p. 15). Tais questões impõem a necessidade de compreender o diálogo existente entre ser social e consciência social, entendendo a relação permanente entre a matéria e o pensamento. Logo, a experiência que surge no ser social, não surge sem pensamento, sem reflexão (VENDRAMINI, TIRIBA, 2014, p. 61). Conforme Thompson (1981, p. 17):

A experiência entra sem bater à porta e anuncia mortes, crises de subsistência, guerra de trincheira, desemprego, inflação, genocídio. Pessoas estão famintas: seus sobreviventes têm novos modos de pensar em relação ao mercado. Pessoas são presas: na prisão pensam de modo diverso sobre as leis. Frente a essas experiências, velhos sistemas conceituais podem desmoronar e novas problemáticas podem insistir em impor sua presença (THOMPSON, 1981, p. 17).

Na formulação desta compreensão, Thomspon dirige sua crítica ao determinismo presente nas tendências "vulgares" ou ortodoxas do marxismo, que tendem, entre outras coisas, a desconsiderar a agência humana na história. Todavia, o autor é categórico em afirmar que os sujeitos não agem livremente, de forma autônoma, mas experimentam suas situações e relações produtivas determinadas (...), e em seguida 'tratam' essa experiência em sua consciência e sua cultura (...) agem, por sua vez, sobre sua situação determinada (THOMPSON, 1981, p. 182). Acrescenta, ainda, que as pessoas lidam com as experiências não apenas no âmbito do pensamento, mas também do sentimento: "Elas também experimentam sua experiência como sentimento e lidam com esse sentimento na cultura, como normas, obrigações familiares e de parentesco, e reciprocidades, como valores ou (através de formas mais elaboradas) na arte ou nas convicções religiosas" (THOMPSON, 1981, p. 189).

Thompson articula experiência e cultura, entendendo que ambas encontram-se intrinsicamente vinculadas a materialidade social, podendo ser compreendidas no contexto amplo do desenvolvimento histórico (VENDRAMINI; TIRIBA, 2014, P. 61); ou ainda, nas palavras de Moraes e Müller (2003, p. 12), constituem "um ponto de junção entre estrutura e processo, entre as determinações objetivas do ser social e a possibilidade do agir e da intervenção humanos". Assim, Thompson recusa tanto as concepções que desmaterializam a vida cultural, como aquelas que a reduzem ao econômico. Segundo ele: 
“(...) no curso real das análises históricas ou sociológicas (bem como políticas) é de grande importância lembrar que os fenômenos sociais e culturais não correm atrás do econômico após longa demora; estão na sua origem, imersos no mesmo nexo relacional" (THOMPSON, 1998, p. 99), sendo que esses fenômenos só adquirem sentido a partir da experiência de homens e mulheres reais.

Para o autor, embora a experiência e a cultura encontrem-se atravessados pela ideologia dominante, discorda da perspectiva althusseriana, de que são meramente imposições do Estado através de seus aparelhos ideológicos. Para Thompson é necessário atentar-se para o caráter contraditório e conflituoso das necessidades materiais e culturais. Novamente, a categoria experiência aparece como importante para revelar como homens e mulheres são capazes de romperem com condições impostas. Nesse sentido, é importante a distinção entre experiência I - experiência vivida e experiência II - experiência percebida ${ }^{3}$.

Moraes e Müller (2007, p. 24) explicam que Thompson considera que as regularidades presentes no interior do ser social, geralmente, são provenientes de causas materiais que independem da consciência ou da intencionalidade. São essas causas que originam a experiência vivida - experiência I -, porém, não são refletidas automaticamente na experiência percebida - experiência II, apenas como reprodução da ideologia. A experiência I pode trazer elementos que levem à recusa e ao questionamento da consciência imposta, podendo gerar transformações no campo da consciência e do agir humano. Nesse sentido, Moraes e Müller (2007, p. 24) ajudam a esclarecer o conceito de experiência bem como a relação dialética estabelecida entre experiência vivida e experiência percebida:

a experiência (...) constitui e nega, opõe e resiste, estabelece mediações, é espaço de prática, intervenção, obstaculização, recusa, é processo de formação de identidades de classe e, poderíamos acrescentar, de gênero, de geração, de etnias. Processos dialeticamente articulados que ela, a experiência, expressa de forma privilegiada.

Wood (2006, p. 90), por sua vez, esclarece que embora Thompson tenha tentado distinguir níveis de experiência (experiência vivida e experiência percebida) - o que poderia indicar a intenção de romper com o elo entre ser social e consciência social - o uso que o autor faz dessa categoria vai justamente em direção contrária; ou seja, em Thompson, a experiência é o termo intermediário entre ser social e consciência social, o meio em que o ser social determina a consciência ou, nas palavras de Thompson (1981, p. 112), "é por meio da experiência que o modo de produção exerce uma pressão determinante sobre outras atividades". Esclarece Wood (2006, p. 90):

O conceito de "experiência", portanto, informa que as "estruturas objetivas" geram efeitos sobre a vida das pessoas; é por isso que, por exemplo, temos classes e não apenas relações de produção. É tarefa do historiador e do sociólogo explorar o que essas "estruturas" fazem à vida das pessoas, como o fazem e como as pessoas reagem - ou, como Thompson poderia ter dito, como as pressões determinantes dos processos estruturados são sentidos e manipulados pelas pessoas.

Para Thompson, embora os eventos sociais e culturais sejam causalmente condicionados por eventos econômicos, possuem autonomia (THOMPSON, 1998, p. 93). Assim, os fenômenos sociais e culturais não podem ser analisados apenas como reflexo imediato da vida econômica. A partir das evidências, é preciso investigar suas 
particularidades e, ao mesmo tempo, como se expressam em condições materiais constituídas historicamente. Assim, os próprios valores de uma sociedade são percebidos entrelaçados com a vida material e como resultado das experiências humanas:

Os valores não são "pensados", nem "chamados"; são vividos, e surgem dentro do mesmo vínculo com a vida material e as relações materiais em que surgem nossas idéias. São as normas, regras, expectativas etc. necessárias e aprendidas (e "aprendidas" no sentimento) no "habitus" de viver; e aprendidas, em primeiro lugar, na família, no trabalho e na comunidade imediata. Sem esse aprendizado a vida social não poderia ser mantida e toda produção cessaria (THOMPSON, 1981, p. 194).

Destaca-se a experiência como um processo de aprendizado. É, nestes termos, que compreende-se a noção de classe social elaborada por Thompson, enquanto um fenômeno histórico, resultado de relações entre os homens reais em contextos reais e constituída num longo processo de fazer-se. Conforme Thompson (1998, p. 102):

Classe é uma formação social e cultural (freqüentemente adquirindo expressão institucional) que não pode ser definida abstrata ou isoladamente, mas apenas em termos de relação com outras classes; e, em última análise, a definição só pode ser feita através do tempo, isto é, ação, reação, mudança e conflito. Quando falamos de uma classe, estamos pensando em um corpo de pessoas, definido sem grande precisão, compartilhando a mesma categoria de interesses, experiências sociais, tradição e sistemas de valores, que tem disposição para se comportar como classe, para definir, a si próprio em suas ações e em sua consciência em relação a outros grupos de pessoas, em termos classistas. Mas classe, mesmo, não é uma coisa, é um acontecimento.

A classe, portanto, constitui-se no seu fazer-se, num processo de aprendizado, num movimento ativo que articula ação humana e condicionamentos sociais. Nesse sentido, o autor entende formações de classe e consciência de classe como um "processo inacabado de relação - de luta com outras classes - no tempo" (THOMPSON, 1981, p. 121). A luta de classes aparece como terreno privilegiado, pois é num processo de luta que as pessoas descobrem a si mesmas como classe, tendo a possibilidade de formação de uma determinada identidade que, por sua vez, posiciona-se contra a identidade de outros homens em função de interesses materiais e culturais opostos (THOMPSON, 2002a, p. 10). Todavia, a luta de classes deriva de determinadas relações de produção que distribuem as pessoas em situações de classe que provocam antagonismos e conflitos de interesses, criando assim condições de luta (WOOD, 2006, p. 76).

Para Thompson, a experiência de classe resulta das relações de produção em que os homens nasceram e, portanto, encontram-se inseridos, independente de suas vontades; já a consciência de classe "é a forma como essas experiências são tratadas em termos culturais: encarnadas em tradições, sistemas de valores, idéias e formas institucionais. Se a experiência aparece como determinada, o mesmo não ocorre com a consciência de classe" (THOMPSON, 2002a, p. 10). Por sua vez, embora a experiência apareça determinada, é ela que pode mediar a constituição da consciência de classe, uma vez que expressa as contradições do ser social no capitalismo. São as pessoas que vivem a experiência da exploração, dos conflitos e das lutas inerentes às relações de produção e que trabalham isso em sua consciência. Assim, é "no meio dessa experiência vivida que toma forma a consciência social e, com ela, a 'disposição de agir como classe"” (WOOD, 2006, p. 89). 
O agir como classe, no entanto, não significa de pronto a consciência de classe, significa perceber a possibilidade de seu desenvolvimento e como ela vai-se constituindo no processo histórico. De acordo com Wood (2006, p. 91), a preocupação de Thompson dirige-se aos processos históricos que intervêm entre as formas de consciências criadas de várias maneiras por situações de classe e a consciência ativa da identidade de classe:

Mais fundamentalmente, identificar classe com um nível particular de consciência, ou com a existência de consciência de classe, seria identificar, como faz Thompson, os complexos processos que ajudam a criar a 'disposição de se comportar como uma classe'.

Essa proposição implica considerar, mesmo nas “formas 'imperfeitas' e 'imparciais' de consciência popular, as expressões autênticas de classe e de luta de classe, válidas nas suas circunstâncias históricas ainda que 'erradas' da perspectiva de desenvolvimentos posteriores ou ideais" (WOOD, 2006, p. 97).

Para a autora, Thompson, ao entender classe como relação e processo, além de afirmar a estrutura objetiva das classes, nega-se a aceitar que elas possam ser simplesmente deduzidas de posições estruturais em relação aos meios de produção ou hipóstase das identidades de classe. Quando se trata de classes como derivadas de posições estruturais, nega-se que elas tenham papel de força motriz no processo histórico e que sofram mutações. O oposto pode ocorrer ao transferir a vontade da ação humana à classe, "uma coisa dotada de identidade estática, cuja vontade é praticamente livre de determinações históricas específicas" (WOOD, 2006, p.92).

É oportuno, ainda, o conceito sobre cultura apresentado por Thompson na introdução de Costumes em Comum (2005), procurando afastar dele "a invocação confortável de um consenso":

Mas uma cultura é também um conjunto de diferentes recursos, em que há sempre uma troca entre o escrito e o oral, o dominante e o subordinado, a aldeia e a metrópole; é uma arena de elementos conflitivos, que somente sob uma pressão imperiosa - por exemplo, o nacionalismo, a consciência de classe ou a ortodoxia religiosa predominante - assume a forma de um "sistema" (THOMPSON, 2005, p. 17).

Thompson observa o perigo de generalizações deslocadas de contextos históricos específicos e que levam a não percepção das contradições, das fraturas e oposições existentes. Assim, Thompson (2005, p. 17), ao estudar a cultura plebéia do século XVIII, recusa-se a tratá-la como situada no "ambiente dos "significados, atitudes, valores"”. Para ele, essa cultura deve ser situada num lugar material determinado: “...localizado dentro de um equilíbrio particular de relações sociais, um ambiente de trabalho de exploração e resistência à exploração, de relações de poder mascaradas pelos rituais do paternalismo e da deferência".

Além disso, condizente com a perspectiva de Thompson sobre a experiência é a explicação que ele realiza, no mesmo texto, sobre certa ambigüidade presente na identidade social de muitos trabalhadores ingleses do séc. XVIII e parte do século XIX. Ao se referir a Gramsci, observa a sua preocupação com a presença de duas consciências em seu homem-massa: a da práxis e a herdada do passado. Destaca que Gramsci viu que a filosofia, espontânea a todas as pessoas, estava fundamentada na linguagem, no sensocomum, no folclore e na religião popular, sendo resultado das experiências compartilhadas no trabalho e nas relações sociais. Conclui: 


\begin{abstract}
Assim, as "duas consciências teóricas" podem ser vistas como derivadas de dois aspectos da mesma realidade: de um lado, a conformidade com o status quo, necessária para a sobrevivência, a necessidade de seguir a ordenação do mundo e de jogar de acordo com as regras impostas pelos empregadores, os fiscais dos pobres etc. De outro lado, o "sensocomum", derivado da experiência de exploração, dificuldades e repressão compartilhada com companheiros de trabalho e os vizinhos, que expõe continuamente o texto do teatro paternalista à crítica irônica, com menos freqüência, à revolta (THOMPSON, 2005, p. 20-21).
\end{abstract}

Novamente, a experiência aparece em Thompson como a possibilidade aberta de desnudar a exploração sofrida e manifestá-la por meio da resistência, da revolta, ainda que seja inconscientemente.

Em A Formação da Classe Operária Inglesa, organizada em três partes, Thompson mostra o fazer-se da classe operária inglesa no período de 1780 a 1832, de modo a revelar como a consciência de classe desses trabalhadores foi forjada a partir de suas experiências políticas, culturais e econômicas, ou seja, foi se constituindo a partir de um longo processo de aprendizado político. O seu interesse reside em resgatar os esquecidos da história, os considerados perdedores: "Estou tentando resgatar o pobre tecelão de malhas, o meeiro luddita, o tecelão do 'obsoleto' tear manual, o artesão 'utópico' e mesmo o iludido seguidor de Joana Southcott, dos imensos ares superiores de condescendência da posteridade" (THOMPSON, 2002a, p. 13).

Na primeira parte - A árvore da liberdade - Thompson detém-se a analisar os elementos subjetivos que contribuíram para as agitações jacobinas nos anos de 1790 na Inglaterra. Longe de ver nelas apenas um reflexo da Revolução Francesa, Thompson procura nas tradições populares do século XVIII, os elementos para a sua compreensão. Assim, examinou as tradições dos artesãos e artífices urbanos a partir de três elementos: a tradição da Dissidência e sua modificação pelo revivalismo metodista; as tradições combinadas na idéia do "direito de nascimento" do homem inglês e a ambígua tradição da turba do século XVIII (THOMPSON, 2002a, p. 23). O autor trata dessas tradições buscando apreender suas contradições. Percebe, por exemplo, o metodismo em suas tendências autoritárias e libertárias; analisa o comportamento subpolítico das massas, mostrando que mesmo entre aqueles considerados desarticulados, desordeiros, superticiosos, passivos, conservavam-se certos valores "- espontaneidade, capacidade para a diversão e lealdade mútua -, apesar das pressões inibidoras de magistrados, usineiros e metodistas (THOMPSON, 2002a, p. 62) e que algumas tradições subpolíticas das massas tiveram influência inicial sobre o movimento operário como os fenômenos dos motins e da turba e as noções populares de um direito de nascimento do inglês. No caso dos motins por alimentos, por exemplo, estava presente uma economia moral "que ensinava ser imoral qualquer método desonesto de aumentar o preço dos alimentos, para se aproveitar das necessidades do povo" (THOMPSON, 2002a, p. 66).

Thompson demonstrou que nas agitações operárias que marcaram o fim do século XVIII na Inglaterra houve o encontro da tradição popular com o movimento jacobino. Por sua vez, as agitações jacobinas tiveram grande alcance para o movimento operário inglês, pois "alterou as atitudes subpolíticas do povo, afetou os alinhamentos de classe e iniciou tradições que se prolongam até o século atual" (THOMPSON, 2002a, p. 111; HOSTINS, 2004, p. 41-42).

Em A Maldição de Adão - segunda parte - conforme relata o próprio Thompson (2002a, p. 12), passa-se "das influências subjetivas para as objetivas", ou seja, as 
experiências mais relevantes de grupos de trabalhadores durante a Revolução Industrial. O autor procura refutar a tese dominante de que o surgimento da classe operária foi uma causa direta da industrialização, mais especificamente da indústria de tecelagem. Primeiramente, Thompson põe em dúvida se de fato foram somente os operários da indústria algodoeira, antes da década de 1840, que formaram o Movimento Trabalhista. Argumenta que as principais manifestações dos trabalhadores do período - jacobinismo, luddismo - foram obras de pequenos artesãos e trabalhadores qualificados de pequenas oficinas. Conforme o autor:

Em muitas cidades, o verdadeiro núcleo de onde o movimento trabalhista retirou suas idéias, organização e liderança era constituído por sapateiros, tecelões, seleiros e fabricantes de arreios, livreiros, impressores, pedreiros, pequenos comerciantes e similares (THOMPSON, 2002b, p. 16).

Dessa maneira, é somente a partir da experiência de diversos grupos de trabalhadores que se pode analisar a formação da classe operária inglesa nesse momento histórico; fato que Thompson observa no período de 1790-1830, no qual se evidencia o aumento da consciência de classe dos trabalhadores e o crescimento das formas correspondentes de organização política e industrial. Consoante com sua perspectiva do agir dos sujeitos na história, para esse autor, o fazer-se da classe operária não foi obra exclusiva e direta do sistema fabril, mas correspondeu a fatos econômicos, políticos e culturais.

As mutáveis relações de produção e as condições de trabalho mutável na Revolução Industrial não foram impostas sobre um material bruto, mas sobre ingleses livres - livre como Paine os legou ou como os metodistas os moldaram. O operário ou o tecedor de meias eram também herdeiros de Bunyan, dos direitos tradicionais nas vilas, das noções de igualdade diante da lei, das tradições artesanais. Eles foram objeto de doutrinação religiosa maciça e criadores de tradições políticas. A classe operária formou-se a si própria quanto foi formada (THOMPSON, 2002b, p. 18).

As mudanças nas relações de produção e nas condições de trabalho, porém, submeteram o povo "à intensificação de duas formas intoleráveis de relação: a exploração econômica e a opressão política" (THOMPSON, 2002b, p. 23). Esse processo contribuiu para que se constituísse uma identidade política, de classe, entre os diversos grupos de trabalhadores.

Depois de examinar as experiências dos trabalhadores rurais, artesãos e tecelões bem como apresentar aspectos do modo de vida dos trabalhadores ingleses durante a Revolução Industrial, Thompson busca analisar o peso da religião metodista sobre o operariado. Embora concorde que o metodismo serviu como autojustificação ideológica para os patrões, buscando por meio das suas pregações disciplinar e moralizar os trabalhadores, esse autor discorda, entretanto, de que essa religião serviu apenas a esses interesses:

Nenhuma ideologia é inteiramente absorvida por seus partidários: na prática, ela multiplica-se de diversas maneiras, sob o julgamento dos impulsos e da experiência. Desta forma, a comunidade da classe operária introduziu nas capelas seus próprios valores de solidariedade, ajuda mútua e boa vizinhança (THOMPSON, 2002b, p. 278). 
Sentimentos de esperança e solidariedade, disciplina, senso de responsabilidade pessoal foram elementos que os rebeldes políticos metodistas levavam para a sua atividade política. Acrescenta, ainda, que a experiência de exploração vivenciada pelos trabalhadores provocava uma leitura da bíblia, onde se encontravam também textos que podiam simbolizar a luta de classes e que, em alguns casos, serviram como discursos políticos. Nesse sentido, poder-se-ia dizer que os trabalhadores não receberam as doutrinas metodistas pura e simplesmente. Pelo contrário, essas doutrinas eram reavivadas pelas experiências dos trabalhadores, adquirindo outros sentidos e significados que serviam, em muitos casos, mais à organização política dos trabalhadores do que simplesmente à sua doutrinação. Thompson reconhece que, mesmo quando o metodismo perdeu sua força junto ao operariado, ao ser suplantado pelo owenismo e os movimentos seculares, ainda assim, mantiveram-se alguns traços herdados dessa religião como o auto-respeito e a autodisciplina de classe. A disciplina da classe trabalhadora poderia ser vista nas marchas realizadas pelos trabalhadores em Newcastle, em 1838 e 1839, caracterizadas por uma intensa ordem. Milhares de artesãos, mineiros e outros trabalhadores marcharam pelas ruas da cidade durante vários dias sem provocar nenhum distúrbio (THOMPSON, 2002b, p. 324).

Na terceira e ultima parte - A força dos trabalhadores - Thompson mostra a resistência e luta dos trabalhadores, às vezes silenciosa, em anos de intensa censura e repressão e como das diversas experiências de grupos de trabalhadores em motins ou organizados em sociedades, sindicatos, igrejas foi emergindo a consciência de classe. Destaca que foram nos anos aparentemente calmos de 1820 que foi se solidificando "uma nova forma de consciência dos trabalhadores em relação aos seus interesses e a sua situação enquanto classe" (THOMPSON, 2002c, p. 303). Foi nesse período, de maneira mais intensa, que a experiência da Revolução Industrial e a experiência do radicalismo popular insurgido e derrotado passam a ser teorizados e que uma cultura política radical vai-se firmando na experiência dos trabalhadores.

Thompson descreve as experiências educativas de diversos grupos de trabalhadores que contribuíram no processo de formação da consciência política da classe operária. Os trabalhadores aprendiam individualmente e em conjunto. Alguns eram autodidatas e se apropriavam individualmente de literaturas radicais. Os analfabetos, por sua vez, valiam-se da capacidade de ouvir para se apropriarem das idéias políticas da época. Apropriavam-se de discursos políticos, das paródias declamadas nas esquinas ou, ainda, valiam-se da leitura de periódicos feitas pelos companheiros de trabalho. A arte popular (teatro, música) também tinha um toque radical. Essa cultura radical atingia principalmente os trabalhadores mais qualificados, entretanto, não passava incólume pelas massas.

Para compreender esse processo na sua amplitude, faz-se necessário um retorno ao passado - ao século XVII e suas tradições populares; nele foi se formando a nova consciência dos trabalhadores frente à experiência da revolução industrial. É a partir disso que, conforme Thompson (2002c, p. 411), essa consciência pode ser vista sob dois aspectos:

De um lado, havia uma consciência da identidade de interesses entre trabalhadores das mais diversas profissões e níveis de realização, encarnada em muitas formas institucionais e expressa, numa escala sem precedentes, no sindicalismo geral de 1830-34 (...).

Por outro lado, havia uma consciência da identidade dos interesses da classe operária, ou "classes produtivas", enquanto contrários aos de 
outras classes; dentro dela, vinha amadurecendo a reivindicação de um sistema alternativo.

Vendramini (2004, p. 32) comenta que Thompson volta às experiências passadas articuladas com as do presente para apreender a emergência dessa nova forma de consciência dos trabalhadores:

Percebe as mudanças e o sentido histórico das associações e experiências coletivas: dos confrontos pessoais aos embates massivos impessoais do futuro; das atitudes subpolíticas à autoconsciência de classe; da experiência da Turba às multidões revolucionárias; da destruição das máquinas à luta contra as relações exploradoras do capitalismo industrial.

Em A Formação da Classe Operária Inglesa, portanto, é possível entender como Thompson utiliza-se da categoria de experiência articulada à de cultura, sem, no entanto, abrir mão de percebê-las em seus nexos com a materialidade social. É a partir dessa articulação, observada num diálogo entre passado, presente e futuro e na relação dialética entre ser social e consciência social, que o autor afirma o fazer-se da classe operária inglesa na transição entre os séculos XVIII e XIX, nos quais as experiências dos trabalhadores forjaram, no processo histórico, a consciência de classe. Ao tratar classe social como um fenômeno histórico, "definida pelos homens enquanto vivem sua própria história", Thompson afirma a realidade histórico-social como um movimento contínuo e sujeita às transformações oriundas das lutas de classes. Disso resulta a sua preocupação metodológica de que, para ter validade, toda categoria teórica deva ser considerada histórica. É importante, ainda, a ênfase de Thompson, clara na análise que faz nessa obra, em relação aos perigos das generalizações, pois elas podem desconsiderar as experiências dos sujeitos bem como sua diversidade e não deixar espaço para os conflitos e contradições (HOSTINS, 2004, p. 49).

\section{A socialização como experiência}

A partir da perspectiva teórica de Thompson, pergunta-se: como esse autor poderia contribuir com reflexões sobre os processos de socialização?

Primeiramente, é importante considerar que não existe no conjunto da obra de Thompson uma preocupação específica com a educação. Entretanto, é salutar que este historiador, além da experiência como intelectual vinculado a universidade e a militância política, tenha dedicado parte da sua vida a educação de adultos, em cursos "extramuros" destinados a sindicalistas e trabalhadores, sendo que desta experiência, segundo o próprio Thompson, surgiu a elaboração da Formação da classe operária inglesa, publicado pela primeira vez em $1963^{4}$. Considerando a educação de adultos, Thompson elaborou algumas das reflexões presentes em palestra que foi proferida em Leeds, em 1968 e depois incluída, na introdução de Os Românticos e que intitulou-se Educação e experiência, onde destaca:

O que é diferente acerca do estudante adulto é a experiência que ele traz para a relação. A experiência modifica, às vezes de maneira sutil e às vezes mais radicalmente, todo o processo educacional; influencia os métodos de ensino, a seleção e o aperfeiçoamento dos mestres e o currículo, podendo até mesmo revelar pontos fracos ou emissões nas disciplinas acadêmicas tradicionais e levar à elaboração de novas áreas de estudo (THOMPSON, 2002, p. 13). 
Para Carmo (2007, p. 20), encontra-se presente na nota acima uma noção de experiência que relaciona-se ao que realmente é vivido pelos seres sociais e que modifica efetivamente a consciência social e o processo educacional. "Pela experiência e pela educação, há uma relação profunda e dinâmica entre os seres sociais e a consciência social que altera a todo o momento o que é pensado e sentido na vida social".

Deste modo, Thompson fornece elementos para pensar os processos de socialização a partir da experiência de homens e mulheres concretos. Distanciando-se de uma perspectiva que vê a socialização como um processo educativo em que os indivíduos apenas receberiam valores, normas, regras, formas de comportamentos ou que afirma a socialização apenas como inculcação ideológica, Thompson, por meio da categoria experiência, fornece elementos para analisar a socialização a partir da dialética entre ser social e consciência social e o agir dos sujeitos nos processos educativos em que se encontram inseridos. Nesses termos, falar sobre socialização ou experiência é dizer sobre o processo de formação humana, especialmente aqueles que dizem respeito a coletivos:

Ao refletir sobre a formação humana, toma assento a palavra coletividade. Há diversas formas e espaços de vivenciar experiências, de aprender com elas e de lhes dar sentido, mas é indiscutível que o coletivo, pensado aqui como coletivo que reúne as pessoas em torno de objetivos comuns, em torno de algo que os identifica, permite a vivência de experiências que podem vir a se tornar emancipatórias. (VENDRAMINI, 2004, p. 35).

Além disso, permite entender que os processos de socialização, ainda que determinados em última instância pela materialidade social encontram-se perpassados pelo político e cultural e que fazem parte do processo histórico. Entender a socialização como experiência é desvendar as contradições que perpassam os processos educativos e, ao mesmo tempo, atentar para como os sujeitos são educados e se educam num determinado contexto histórico. Trata-se de entender as experiências sócio-educativas construídas nas relações estabelecidas no interior das diversas instituições que os sujeitos estão inseridos que, ao mesmo tempo, reproduzem valores e práticas presentes na sociedade de classes, mas também podem possibilitar a vivência de novos valores e práticas. Nesse sentido, o uso da categoria experiência reforça a concepção de que os processos educativos não acontecem apenas nas instituições educacionais formais, mas também dizem respeito às aprendizagens da própria vida, englobando relações pessoais, de trabalho, políticas etc. Desta forma, a educação não se limita ao espaço escolar, mas liga-se a experiência de vida dos sujeitos, oferecendo diferentes e conflitantes oportunidades socializadoras.

Neste sentido, pode-se entender a preocupação de Thompson com a educação formal que historicamente tem se divorciado da experiência. Chama a atenção para a relação dialética entre experiência e educação, destacando a necessidade dos processos de escolarização, especialmente de adultos, estarem abertos a experiência. Referindo-se as universidades afirma que estas "precisam do contato de diferentes mundos de experiência, no qual ideias são trazidas para prova da vida" ou ainda, que deveriam ser "uma porta de saída para o conhecimento e as competências, uma porta de entrada para a experiência e a crítica" (THOMPSON, 2002, p. 45).

Por fim, é importante considerar que a socialização entendida como experiência, especialmente aquela que diz respeito à formação política se constitui em relações que não emergem direta e necessariamente da ação política, mas de uma construção processual de educação, de práticas, valores, ideologias, bem como de ações. Este conjunto é formador 
do individuo, com a capacidade de torná-lo ou não agente de práticas emancipatórias, no sentido de se contrapor à ordem dominante. Neste sentido, a socialização como experiência liga-se a constituição das classes sociais e da luta de classes. Logo, como destacou Vendramini e Tiriba (2014, p. 64), esta concepção afasta-se das noções que tratam a experiência como sinônimo de empirismo, pragmatismo ou como aprender pela experiência tão presentes nas práticas pedagógicas atuais. Em Thompson, a experiência é engendrada no processo histórico.

\section{Considerações Finais}

Este trabalho buscou, a partir da categoria experiência, apresentar as possíveis contribuições de E. P. Thompson para a análise dos processos educacionais.

Thompson, sem abandonar os princípios ontológicos de Marx, procurou romper e superar um marxismo dogmático e determinista, o que expressou, sobretudo, nas críticas feitas a Althusser. Propôs, como historiador e pesquisador, colocar-se em permanente diálogo com Marx, de modo a permanecer fiel ao próprio legado desse autor, ou seja, a perspectiva de análise da condição histórica da realidade e, portanto, sujeita a mudanças.

É nesse sentido que Thompson propõe a utilização da categoria experiência para a análise da realidade histórico-social. Para ele, por meio dessa categoria, pode-se perceber o diálogo entre ser social e consciência social. Além disso, recupera o papel dos sujeitos na história, enfatizando a importância de entender como os homens e mulheres reais, em contextos determinados material e culturalmente, "tratam" a experiência e lidam com ela no plano do pensamento e do sentimento. A categoria experiência permite ainda, perceber o entrelaçamento de fatores econômicos, sociais e culturais, desviando-se, portanto, de uma análise determinista e mecânica.

Considerando esta perspectiva, conclui-se que este autor pode contribuir para a análise dos processos educacionais na atualidade. A partir da compreensão da educação como socialização, acredita-se que por meio da categoria experiência, pode-se analisá-la a partir da dialética entre ser social e consciência social, levando em conta o agir dos sujeitos nos processos educativos em que se encontram inseridos. Neste sentido, trata-se de buscar entender os processos contraditórios em que os homens e mulheres se educam e são educados e atentar para as possibilidades de conservação e mudança.

\section{Referências}

BERGER, Peter; LUCKMANN, Thomas. A construção social da realidade. 21. ed. Petrópolis: Vozes, 2002.

CARMO, jefferson Carriello do. Possíveis contribuições de Edward Palmer Thompson para a História da Educação. Revista HISTEDBR On-line, Campinas, n 27, p. 9-27, set. 2007.

DURKHEIM, Emile. Educação e sociologia. São Paulo: Melhoramentos, 1975.

EISENSTADT, S. N. De geração a geração. São Paulo: Perspectiva, 1976.

FORTES, Alexandre; NEGRO, Antonio; FONTES, Paulo. Pecularidades de E. P. Thompson. In.: NEGRO, Antonio Luigi; SILVA, Sergio (orgs.). E. P. Thompson: as 
peculiaridades dos ingleses e outros artigos. 3. ed. Campinas: Unicamp, 1998. n. 10, v. 2, p. 11-46. (Coleção Textos Didáticos)

HOSTINS, Regina Célia Linhares. O modo de fazer pesquisa de um historiador. Esboços, Florianópolis, n. 12, p. 37-52, 2004.

KOSIK, Karel. Dialética do concreto. 2. ed. Rio de Janeiro: Paz e Terra, 1995.

LÖWY, Michael. Por um marxismo crítico. Lutas Sociais, São Paulo, 1997, n. 3.

MARTINS, Suely Aparecida. A formação política da juventude do Movimento Sem Terra no Estado do Paraná. Tese de Doutorado (Doutorado em Sociologia Política). Florianópolis: Centro de Filosofia e Ciências Humanas, UFSC, 2009.

MORAES, Maria Célia Marcondes de; MÜLLER, Ricardo Gaspar. Tempos em que a "razão deve ranger os dentes": E.P. Thompson, história e sociologia. In.: CONGRESSO BRASILEIRO DE SOCIOLOGIA, 11, Campinas. Anais.... Campinas: Unicamp, 2003. p. 2-17.

E. P. Thompson e a pesquisa em ciências sociais. In.: ENCONTRO ANUAL DA ANPOCS, 31, 2007, Caxambu. Anais.... Caxambu/MG: ANPOCS, 2007. p. 2-30.

SILVA, Sérgio. Thompson, Marx, os marxistas e os outros. In.: NEGRO, Antonio Luigi; SILVA, Sergio (orgs.). E. P. Thompson: as peculiaridades dos ingleses e outros artigos. 3. ed. Campinas: Unicamp, 1998. n. 10, v. 2. p. 47-56 (Coleção Textos Didáticos).

THOMPSON, E. P. A formação da classe operária inglesa I: a árvore da liberdade. 4. ed. Rio de Janeiro: Paz e Terra, 2002a.

. A formação da classe operária inglesa II: a maldição de Adão. 4. ed. Rio de Janeiro: Paz e Terra, 2002b.

A formação da classe operária inglesa III: a força dos trabalhadores. 4. ed. Rio de Janeiro: Paz e Terra, 2002c.

A miséria da teoria ou um planetário de erros. Rio de Janeiro: Zahar, 1981.

As peculiaridades dos ingleses. In.: NEGRO, Antonio Luigi; SILVA, Sergio (orgs.). E. P. Thompson: as peculiaridades dos ingleses e outros artigos. 3. ed. Campinas: Unicamp, 1998. n. 10, v. 1 (Coleção Textos Didáticos).

Costumes em comum: estudos sobre a cultura popular tradicional. São Paulo: Companhia das Letras, 2005.

Tradición, revuelta y consciencia de clase. Barcelona: Editorial Crítica, 1979.

Os românticos: a Inglaterra na era revolucionária. Rio de Janeiro: Civilização Brasileira, 2002. p. 13-47 
VENDRAMINI, Célia Regina. Experiência humana e coletividade em Thompson. Esboços, Florianópolis, n. 12, p. 25-36, 2004.

; TIRIBA, Lia. Classe, cultura e experiência na obra de E. P. Thompson: contribuições para a pesquisa em educação. Revista HISTEDBR On-line, Campinas, n 55, p. 54-72, mar. 2014.

\section{Notas}

${ }^{1}$ Versão deste artigo foi publicada no livro de circulação local Conhecimentos, (re)construções e práticas pedagógicas. Francisco Beltrão: Unioeste, 2009 e nos Anais do V Encontro Brasileiro de Educação e Marxismo - EBEM, 2011.

${ }^{2}$ Professora do Curso de Pedagogia e do Programa de Pós-Graduação em Educação da Universidade Estadual do Oeste do Paraná, Campus de Francisco Beltrão. E-mail: martins_sue @ hotmail.com

${ }^{3}$ Esta distinção foi apresentada por Thompson em um Seminário em Oxford, na Inglaterra, em 1979, e ofereceu esclarecimentos sobre a relação experiência e cultura em resposta às críticas suscitadas no debate pelos demais expositores (MORAES; MÜLLER, 2007, p. 21).

${ }^{4}$ Sobre a vida de Thompson ver FORTES, Alexandre; NEGRO, Antonio; FONTES, Paulo (1998, p. 11-46). 